\title{
Bilangan 5:11-31: Ritual Sotah sebagai Terobosan Budaya di Timur Tengah Kuno
}

\section{Numbers 5:11-31: Sotah as a Cultural Breakthrough in the Ancient Near East}

\author{
Steven Yong \\ Sekolah Tinggi Teologi Reformed Indonesia \\ Korespondensi: steven@reformedindonesia.ac.id
}

\begin{abstract}
Abstrak: Bilangan 5:11-31 dapat menimbulkan kecurigaan tentang adanya praktik seksisme, penindasan atau pelecehan terhadap wanita. Hal ini bisa dimengerti jika Mishnah menjadi rujukan yang kemudian dijadikan tolok ukur untuk menafsir bagian Alkitab terkait. Dari penggambaran Mishnah Sotah, wanita yang tertuduh melakukan zina dipermalukan dan diperlakukan hampir sama seperti seorang pelacur. Artikel ini berusaha untuk menunjukkan perspektif yang lain dalam mengerti ritual Sotah dalam Bilangan 5:11-31. Dengan menggunakan metode kajian sosiologis, artikel ini akan mengidentifikasi masalah sosiologis yang dituduhkan terhadap teks Bilangan tersebut berdasarkan penjelasan traktat Sotah dalam Mishnah. Kemudian, posisi wanita dalam dunia Timur Dekat Kuno akan dijelaskan berdasarkan konteks budayanya. Akhirnya, dengan menimbang inferioritas wanita dalam dunia Timur Dekat Kuno dan perbandingan antara ritual Sotah dalam Alkitab dengan ritual sejenis dan setempat, maka artikel ini berargumen bahwa teks Bilangan 5:11-31 dapat dilihat sebagai terobosan budaya dalam membela wanita yang secara budaya pada masa itu dianggap sebagai kaum yang inferior.
\end{abstract}

Kata-kata kunci: Bilangan 5:11-31, Sotah, Zina, Timur Dekat Kuno, Seksisme

\begin{abstract}
Numbers 5:11-31 could be interpreted as a kind of sexism and repression to women. In the Mishnaic tradition, the passages indeed are being understood and developed in such manner. From tractate Sotah in Mishnah, the suspected adulterous wife indeed is ashamed and treated as a prostitute. This article seeks to present another perspective on the passage. This article uses the sociological study method to identify the sociological problems alleged against the passage based on the explanation of the Sotah tractate in the Mishnah. Afterward, the inferior position of women in the ancient Near East will be explained as a cultural context to understand the passage better. Finally, considering this cultural context and comparing the Sotah ritual with the common rituals in the ancient Near East, this article argues that Numbers 5:11-31 could be seen as a cultural breakthrough to protect women, which are considered marginalized.
\end{abstract}




\section{PENDAHULUAN}

Timothy Ashley mensinyalir bahwa teks Bilangan 5:11-31 sudah diperdebatkan sejak lama. ${ }^{1}$ Secara sosiologis, muncul persoalan keadilan dari apa yang kemudian dikenal sebagai ritual Sotah dalam teks tersebut, terutama mengenai aspek perlakuan yang semenamena terhadap wanita saat menjalani Taurat yang dimaksud. ${ }^{2} \mathrm{Hal}$ ini diperparah dengan penjelasan terhadap Taurat tersebut dalam Mishnah Sotah. Dari kacamata Mishnah Sotah, sang wanita tersangka tampak dihina, diperlakukan dengan tidak layak, bahkan hampir disamakan dengan pelacur. Jika Mishnah Sotah memang menjelaskan ritual Sotah dalam Bilangan 5, maka benarlah perkataan seorang cendekia feminis, Rebecca Alpert, "Tidak ada yang bisa menghindari seksisme yang data-datanya jelas ada dalam Alkitab."3

\section{METODE PENELITIAN}

Menyadari bahwa teks tersebut bukan merupakan produk kekinian, artikel ini akan menyuguhkan keunikan dari ritual Sotah dalam Bilangan 5 dengan melakukan kajian secara sosiologis dari budaya setempat dan sezaman. Setelah menelaah isu sosiologis yang dipermasalahkan dalam teks Bilangan dan penjelasannya dalam Mishnah Sotah, stereotip terhadap wanita dalam dunia Timur Dekat Kuno akan diberikan sebagai latar belakang budaya yang berlaku pada saat itu. Terakhir, ritual Sotah dalam Alkitab yang melibatkan wanita akan dibandingkan dengan ritualritual serupa dalam dunia Timur Dekat Kuno.

\footnotetext{
${ }^{1}$ Timothy R. Ashley, The Book of Numbers, NICOT (Grand Rapids: Eerdmans, 1993), 119.

${ }^{2}$ Ashley, The Book of Numbers, 122.

${ }^{3}$ Rebecca T. Alpert, "The Sotah Revisited," The Reconstructionist 53 (1988): 32-33. Sotah dalam tradisi literatur Talmud merupakan istilah yang dikenakan kepada seorang wanita yang dicurigai telah melakukan perzinahan dan yang harus menjalani suatu ritual yang akan menunjukkan apakah ia bersalah atau tidak.

${ }^{4}$ Philip J. Budd, Numbers, vol. 5, WBC (Waco: Word, 1984), 65.

${ }^{5}$ Dari akar kata inilah istilah Sotah berasal.
}

Bukannya mendukung stereotip antiwanita seperti yang dituduhkan, studi ini berargumen bahwa ritual Sotah dalam Alkitab justru adalah terobosan budaya yang unik yang diinstitusikan TUHAN untuk melindungi wanita, kaum yang dipandang sebelah mata dalam dunia Timur Dekat Kuno.

\section{HASIL DAN PEMBAHASAN}

\section{Teks Bilangan 5:11-31 dan Mishnah Sotah}

Bilangan 5:11-31 ada dalam bingkai konteks pasal 5 mengenai kekudusan dari umat. Untuk itu, permulaan di ayat 1-10 berbicara tentang kenajisan dan penebusan salah. ${ }^{4}$ Secara spesifik, ayat 11-31 menyebutkan suatu ritual tentang perkara seorang istri yang dicurigai telah melakukan zina: שטה (sth). ${ }^{5} \mathrm{Di}$ sebut demikian sebab si tersangka adalah wanita yang tidak setia, seorang yang berbalik dari suaminya. ${ }^{6}$ Secara teologis, bagian ayat ini memperlihatkan keseriusan moral dalam pernikahan kudus umat. ${ }^{7}$ Persoalan ini dibawa ke hadapan imam karena ada unsur kecemburuan di pihak suami (ay. 14-15).

Beberapa penafsir mempermasalahkan apa penyebab dari kecemburuan itu. William McKane dan Baruch Levine mengasumsikan kehamilan sebagai pemicu persoalan cemburu ini. ${ }^{8}$ Berbeda dengan mereka, G.R. Driver tidak membuat mutlak kondisi si wanita entah

\footnotetext{
${ }^{6}$ Lisa Gruschcow, Writing the Wayward Wife: Rabbinic Interpretations of Sotah, Ancient Judaism and Early Christianity 62 (Leiden: Brill, 2006), 1, https://doi.org/10.1163/ 9789047417811.

${ }^{7}$ Budd, Numbers, 5:66.

${ }^{8}$ William McKane, "Poison, Trial by Ordeal and the Cup of Wrath," Vetus Testamentum 30, no. 4 (1980): 474, https://doi.org/10.1163/156853380X00434; Baruch Levine, Numbers 1-20: A New Translation with Introduction and Commentary, Anchor Bible Commentary (New York: Yale University Press, 1993), 181, 193.
} 
dia sedang atau tidak hamil. ${ }^{9}$ Tikva FrymerKensky berargumen bahwa tidak ada alasan untuk beranggapan bahwa si wanita itu sedang hamil. ${ }^{10}$ Agaknya memang berlebihan jika seorang wanita yang sedang hamil di luar nikah masih dalam status dicurigai. Bagaimanapun, apakah benar wanita itu hamil atau tidak, dasar dari ritual Sotah ini ada dua: kecemburuan dan ketidakpastian. ${ }^{11}$

Untuk menyelesaikan masalah ini, hukum Taurat mengharuskan sang suami yang dikuasai oleh "roh cemburu" itu untuk membawanya kepada imam di kemah suci. Di sana, korban sajian cemburuan yang dibawa oleh sang suami berupa tepung jelai tanpa minyak dan kemenyan akan diunjukkan lalu dibakar sebagian. Sang imam akan mengurai rambut tersangka, membuatnya bersumpah bahwa ia tidak melakukan hubungan seksual dengan pria lain. Sebuah gulungan yang tertulis suatu kutuk dicelupkan ke dalam air yang dicampur dengan debu kemah suci sehingga tintanya larut bersama dengan semuanya itu, dan sang imam akan membuat wanita itu meminum larutan tersebut.

Setelah itu, keadilan TUHAN akan ditunjukkan dalam perkara tersebut lewat hasil dari ritual yang telah dilakukan oleh sang imam. Nasib dari wanita tersangka itu akan ditentukan oleh TUHAN lewat efek dari campuran cairan, yakni air pahit yang terkutuk, yang

\footnotetext{
${ }^{9}$ G.R. Driver, "Two Problems in the Old Testament Examined in the Light of Archeology" Syria 33, no. 1/2 (1956): 73-77, http://www.jstor.org/stable/4197001.

${ }^{10}$ Tikva Frymer-Kensky, "The Strange Case of the Suspected Sotah," Vetus Testamentum 34, no. 1 (1984): 19 catatan 15, https://doi.org/10.1163/156853384X00025.

${ }^{11}$ Gruschcow, Writing the Wayward Wife, 36.

${ }^{12}$ Ini ditunjukkan lewat kalimat eufemisme "paha yang mengempis dan perut yang mengembung." Hal ini juga sesuai dengan lawan dari akibat yang dihasilkan oleh air kutuk itu bagi wanita yang tidak bersalah, yakni kesuburan (bdk. Bilangan 5:28, LAI: "akan dapat beranak").

${ }^{13}$ Perlu diperhatikan bahwa urutan ritual yang diberikan dalam Mishnah Sotah berbeda secara signifikan dibanding dengan yang tercatat dalam Taurat. Tidak hanya itu, jika membawa sang wanita di hadapan Allah dan mengurai rambutnya adalah tahap awal dari ritual meminum larutan
}

telah diminum olehnya. Setelah meminumnya, jika ternyata bersalah, wanita itu akan menjadi mandul. ${ }^{12}$ Namun, jika tidak bersalah, air itu tidak akan mencelakainya, malah akan membuatnya subur.

Penjelasan diberikan dalam sebuah Mishnah terhadap isi Taurat dalam Bilangan 5 tersebut. ${ }^{13}$ Hal yang menimbulkan persoalan sosiologis adalah bagaimana cara Mishnah tersebut menggambarkan proses ritual Sotah yang dijalankan oleh seorang wanita tertuduh. Dalam tulisan itu tercatat bahwa saat melakukan ritual, setelah mengurai rambut sang wanita, imam yang bertugas lalu merobek pakaiannya (Mishnah Sotah 1:5).

\section{A Priest lays hold on her garments-if they are torn they are torn, if they are utterly rent they are utterly rent-so that he lays bare her bosom. Moreover he loosens her hair. $R$. Judah says: If her bosom was comely he did not lay it bare; if her hair was comely he did not loosen it. ${ }^{14}$}

Sang imam kemudian menanggalkan semua perhiasan yang dikenakan oleh si wanita tersangka untuk mempermalukannya, mengikatnya, lalu mengundang semua orang untuk menyaksikan peristiwa tersebut (ay. 6). ${ }^{15}$

\section{If she bore ornaments of gold and chains and nose-rings and finger-rings, they were taken}

kutuk, pada Mishnah bagian ini dikembangkan sampai bisa berdiri sendiri sebagai suatu ritual tersendiri yang bersifat penghinaan. Untuk daftar perbedaan antara catatan Mishnah dan Taurat, lih. Ishay Rosen-Zvi, The Mishnaic Sotah Ritual: Temple, Gender and Midrash, Supplements to the Journal for the Study of Judaism (Leiden: Brill, 2012), 67.

${ }^{14}$ H. Danby, ed., The Mishnah (London: Oxford University Press, 1933), 293-294.

${ }^{15}$ Kata menanggalkan di sini kemungkinan lebih bersifat konsekuensi daripada kesengajaan, sesuai dengan bahasa yang digunakan dalam Mishnah, "And a priest would hold her garments - if they tore, they tore, if they ripped at the seam, then they ripped at the seam-until he uncovered her bossom and loosen her hair." Lih. Rosen-Zvi, The Mishnaic Sotah Ritual, 69-70. 
from her to shame her. He then brought an Egyptian rope and tied it above her breasts. Any that wished to behold came and beheld, excepting her bondmen and bondwomen, since with them she feels no shame. And all women are allowed to behold her, for it is written, That all women may be taught not to do after your lewdness. ${ }^{16}$

Perlakuan ini dianggap tidak wajar dan berlebihan karena tidak ada catatan mengenai hukuman serupa yang dikenakan kepada seorang pria. Malahan, posisi wanita yang inferior dibanding dengan pria dalam dunia $\mathrm{Ti}$ mur Dekat Kuno menambah kecurigaan bahwa teks Bilangan 5:11-31 yang dijelaskan juga dalam traktat Sotah mengandung unsur seksisme. Berikut akan dipaparkan posisi seorang wanita dalam masyarakat Timur Dekat Kuno.

\section{Posisi Wanita dalam Dunia Timur Dekat Kuno}

Dalam keluarga di Timur Dekat Kuno, seorang wanita yang sudah menikah terikat sepenuhnya dengan suaminya sebagai sang pemegang hak dalam institusi pernikahan atas istrinya. ${ }^{17}$ Akibatnya, kasus perzinaan sendiri cenderung dibebankan pada seorang wanita yang telah menikah atau bertunangan tetapi melakukan hubungan seksual dengan pria selain dari suami atau tunangannya. Sebaliknya, bisa diasumsikan bahwa secara budaya, seorang pria di Timur Dekat Kuno dapat berhubungan seksual dengan wanita mana pun kecuali dengan mereka yang sudah menikah. ${ }^{18}$ Apabila seorang istri berzina

\footnotetext{
${ }^{16}$ Danby, The Mishnah, 294.

${ }^{17}$ Hennie J. Marsman, Women in Ugarit and Israel: Their Social and Religious Position in the Context of the Ancient Near East (Leiden: Brill, 2003), 169.

${ }^{18}$ Marten Stol, Women in the Ancient Near East (Boston: De Gruyter, 2016), 234.

${ }^{19}$ Marsman, Women in Ugarit and Israel, 169.

${ }^{20}$ Jeffrey H. Tigay, Deuteronomy, The JPS Torah Commentary (Philadelphia: Jewish Publication Society, 1996), 71.
}

dengan pria lain, ia dapat dijatuhi hukuman mati. ${ }^{19}$ Ditambah lagi, dalam konteks budaya masyarakat Timur Dekat Kuno yang menganut poligami, seorang pria memiliki hak penuh atas istrinya, tetapi tidak sebaliknya. Maka, keturunan yang diperhitungkan adalah yang berasal dari silsilah seorang ayah, bukan ibu. $^{20}$

Standar yang dikenakan kepada seorang istri dalam hukum di Babel juga tampak memberatkan (Hukum Hammurabi §141-143). ${ }^{21}$ Seorang istri yang tidak bersikap dengan baik, misalnya menelantarkan rumah dan suaminya saja bisa dengan mudah diceraikan dengan tidak memberikan apa-apa kepadanya. Atau, suaminya bisa menikahi wanita lain tanpa cerai dan dengan demikian menurunkan derajat istri pertamanya itu. Jika istri menuntut cerai dan ternyata kedapatan bahwa dialah yang menelantarkan istri dan suaminya, maka ia dapat ditenggelamkan oleh otoritas setempat. ${ }^{22}$

If the wife of a man who is living in his house, set her face to go out and play the part of a fool, neglect her house, belittle her husband, he shall let her to account; if her husband say "I have put her away," he shall let her go. On her departure nothing shall be given to her for her divorce. If her husband say: "I have not put her away," her husband may take another woman. The first woman shall dwell in the house of her husband as a maid servant (Hukum Hammurabi §141).

If she have not been a careful mistress, have gadded about, have neglected her house and

\footnotetext{
${ }^{21}$ Semua kutipan ke Hukum Hammurabi dalam artikel ini diambil dari Robert Francis Harper, The Code of Hammurabi: King of Babylon about 2250 B.C. (Chicago: University of Chicago Press, 1904). Pengutipan dari Hukum Hammurabi ini menggunakan penomoran bagian $\S$.

${ }^{22}$ Elizabeth Mary MacDonald, The Position of Women as Reflected in Semitic Codes of Law (Toronto: University of Toronto Press, 1931), 19.
} 
have belittled her husband, they shall throw that woman into the water (Hukum Hammurabi §143).

Dalam hal ketidaksetiaan, wanita selalu dirugikan dalam dunia Timur Dekat Kuno. Seorang pria tidak akan dipersalahkan jika ia melirik seorang wanita dengan bernafsu. Hukum Hammurabi $\$ 141$ bahkan tidak mensyaratkan apapun, selain kehilangan semua pemberian kepada calon ayah mertuanya, jika seorang pria membatalkan pernikahan hanya oleh karena ia berhasrat dengan wanita lain. Namun, seorang wanita bisa dilabel sebagai wanita tunasusila dalam perkara yang sama. ${ }^{23}$

Wanita dalam dunia Alkitab juga digambarkan sebagai pihak yang menginisiasi tindakan perzinaan. Alkitab Ibrani, misalnya, menceritakan istri Potifar yang menggoda Yusuf di Mesir (Kej. 39). Amsal 7 memperingatkan seorang muda agar tidak jatuh ke dalam jerat godaan seorang wanita. Tidak heran jika dalam tradisi suku Beduin wanita yang terlibat kasus perzinaan dengan mudah dihukum mati oleh suami atau saudara laki-lakinya. Tidak demikian pada pelaku pria. ${ }^{24}$

\section{Perbandingan Ritual Sotah dengan Ritual Setempat}

Menimbang posisi wanita dalam konteks budaya Timur Dekat Kuno dan bagaimana teks Bilangan 5:11-31 itu ditulis, ada beberapa pendekatan yang bisa dilakukan sebagai penjelasan dari isi Taurat tersebut. Pertama, bahwa kasus yang sedang dihadapi di sini adalah kasus kecurigaan. Perlu dipahami bahwa sistem hukum masyarakat Timur Dekat Kuno belum dapat membuktikan kasus kecurigaan itu dengan sepantasnya.

Itulah sebabnya, dalam teks Bilangan 5 ada beberapa klausa yang harus dipenuhi agar kasus perzinaan ini bisa diproses lewat ritual

\footnotetext{
${ }^{23}$ Stol, Women in the Ancient Near East, 236.
}

Sotah. Setidaknya, ada empat klausa penjelas yang harus dipenuhi oleh sang pelaku agar seorang wanita tersebut bisa dikatakan terlibat kasus perzinaan: (a) berbuat serong, (b) tidak setia terhadap suaminya, (c) bersetubuh dengan pria lain, dan (d) mencemarkan diri.

Tidak hanya itu, untuk bisa mengaktualisasi ritual Sotah, kasus perzinaan itu haruslah tanpa saksi atau bukti dari pihak yang merasa menjadi korban. Kasus ini dikatakan tanpa bukti jika memenuhi sedikitnya 3 klausa: (a) suaminya tidak mengetahui perbuatan istrinya itu, (b) perzinaan itu dirahasiakan, (c) tidak ada saksi terhadap dia, dan (d) wanita itu tidak kedapatan sedang melakukan zina.

Terakhir, harus ada kondisi yang menyebabkan ritual Sotah itu tak terhindarkan. Bilangan 5:14 menjelaskan bahwa setelah kedua syarat di atas telah terpenuhi, dan sekarang sang suami dalam kondisi dipenuhi rasa cemburu atau curiga, entah kecurigaan itu benar atau tidak, maka di ayat 15 barulah pria itu dapat membawa istrinya itu kepada imam untuk diadili.

Jadi, seorang wanita tidak dengan mudah bisa diseret untuk diadili dengan ritual Sotah. Dari syarat-syarat yang telah dikemukakan di atas bisa dimengerti bahwa Bilangan 5:11-31 memberikan batasan agar seorang wanita jangan sampai oleh karena alasan kecurigaan yang liar dapat dengan segera diadili di hadapan imam. Berbeda dengan ritual Sotah dalam Alkitab yang memberikan batasan-batasan yang jelas, Hukum Hammurabi, misalnya, tidak memberikan syarat-syarat yang harus dipenuhi agar seorang wanita tertuduh dapat diadili selain dari tuduhan itu sendiri dan demi martabat suaminya itu.

If the finger have been pointed at the wife of a man because of another man, and she have not been taken in lying with another man, for 
her husband's sake she shall throw herself into the river (Hukum Hammurabi §132).

Bukankah perzinaan dalam Alkitab termasuk ke dalam kasus yang berat di mana konsekuensinya adalah hukuman mati bagi tersangka (lih. Im. 18:20)? Dalam Ulangan 22:24, tersangka kasus perzinaan bisa dihukum dengan dilempari batu. Ini merupakan suatu prosedur yang menunjukkan kebencian masyarakat atas tindakan yang dianggap mengancam seluruh bangsa. ${ }^{25}$ Dalam Taurat, larangan berbuat zina adalah bentuk perlindungan atas institusi pernikahan. Pernikahan dipandang sebagai sebuah institusi sakral. Jumlah tulisan dalam Pentateuch untuk membahas kasus ini dengan sendirinya membuktikan kepentingannya sehingga termasuk dalam kategori aturan kekudusan yang ketat berkenaan dengan kemurnian dari pernikahan (lih. misalnya Kel. 20:14; Im. 17-26; 20:1021; Ul. 5:17; 22:13-29). ${ }^{26}$ Oleh sebab itu, sanksi seberat hukuman mati dijatuhkan atas orang yang melakukan zina. Ritual Sotah dalam Bilangan 5 diberikan sebagai bentuk pencegahan agar jangan ada wanita yang ternyata tidak bersalah, namun hanya oleh karena rasa cemburu yang belum terbukti dari sang suami, ia dihukum mati. Lebih dari itu, ritual Sotah ini bahkan dilengkapi dengan batasan-batasan yang pantas bagi si tertuduh. Dengan demikian, klausa-klausa yang disyaratkan dalam Bilangan 5 itu membuat masyarakat yang terikat dengan hukum ini tidak serta merta dapat menghukum mati seorang wanita.

Yang termasuk di dalam kategori sanksi hukuman berat adalah kasus pembunuhan dalam Ulangan 21:1-9. Lebih dari itu, Bilangan 35:31 memberikan penjelasan bahwa keluarga dari korban kasus pembunuhan dilarang untuk menerima uang tebusan sebab kesalah- an seorang pembunuh setimpal dengan hukuman mati. Sifat dari kasus yang dihadapi dalam Bilangan 5 adalah sama dengan Ulangan 21. Sementara sanksi bagi pembunuhan dan perzinaan adalah jelas hukuman mati, tersangka dari kasus Bilangan 5:11-31 itu masih dalam status dipertanyakan sehingga sang tertuduh tidak layak untuk menerima hukuman seberat hukuman mati. Sebagai gantinya, ritual Sotah diberikan lengkap dengan syaratsyaratnya.

Di samping itu, dalam literatur Timur Dekat Kuno diketahui bahwa seorang wanita tidak jarang menjadi tersangka kasus zina hanya oleh karena gosip (Hukum Lipit-Ištar §33).

If (anyone) shall say of the virgin daughter of a man 'she knows the rod', and it is established that she does not know the rod, then he shall pay ten shekels of silver. ${ }^{27}$

Masyarakat Timur Dekat Kuno cenderung mudah untuk membicarakan persoalan kemurnian dari wanita yang sudah menikah seperti tampak pada teks hukum Lipit-Ištar di atas. Hal ini memperparah kecurigaan terhadap wanita yang menjadi tersangka kasus zina. Dalam situasi budaya seperti ini, wanita diharapkan untuk menjaga reputasinya agar tidak menjadi bahan pembicaraan. ${ }^{28}$ Dengan kata lain, bisa dimengerti bahwa seorang wanita yang sudah dicurigai melakukan zina sulit untuk menganulir tuduhan itu.

Karena itu, solusi yang diberikan dalam Bilangan 5:11-31 adalah melalui ritual Sotah dalam penentuan tersangka yang masih belum dapat diidentifikasi. Ritual ini mengasumsikan hadirnya penghakiman ilahi untuk menentukan kasus yang tidak dapat dibuktikan

\footnotetext{
${ }^{27}$ Seperti yang dikutip dalam Stol, Women in the Ancient Near East, 246.

${ }^{28}$ Stol, Women in the Ancient Near East, 246.
}

\footnotetext{
25 Tigay, Deuteronomy, 71.

${ }^{26}$ Michael Fishbane, "Accusations of Adultery: A Study of Law and Scribal Practice in Numbers 5:11-31," Hebrew Union College Annual 45 (1974): 25.
} 
dengan saksi mata. ${ }^{29}$ Ketika seorang wanita yang tertuduh itu tidak bisa menganulir tuduhan dari sang suami yang cemburu dan karena minimnya sarana pembuktian serta terancamnya nyawa sang tersangka akibat kecurigaan yang dilekatkan kepadanya, maka diperlukan alat pembuktian lain yang mengatasi hukum fisik, yakni diselesaikan dengan intervensi metafisik. Dalam kasus kecemburuan terhadap kasus perzinaan yang belum terbukti, dilakukan ritual Sotah, sedangkan dalam kasus Ulangan 21, diadakan doa untuk melakukan pendamaian bagi umat atas perkara pembunuhan seorang yang mati terbunuh di padang. Kunci dari ritual-ritual itu adalah pengakuan bahwa hanya Allah yang dapat menyatakan siapa yang bersalah dan melepaskan yang tidak bersalah. Dengan cara demikian, posisi inferior dari seorang wanita yang terancam dihakimi itu sedang dibela dalam ritual Sotah. Ritual ini merupakan sebuah terobosan budaya pada masa itu untuk melindungi posisi seorang wanita tertuduh.

Kedua, menurut konteks budaya dari teks Bilangan, ritual seperti ini wajar dipraktikkan di sekitar Timur Dekat Kuno. Ritual yang biasa dipraktikkan misalnya dengan menenggelamkan tersangka ke dalam sungai (Hukum Hammurabi §132).

If a man's wife should have a finger pointed against her in accusation involving another male, although she has not been seized lying with another male, she shall submit to the divine River god for her husband. ${ }^{30}$

Dalam Hukum Hammurabi, praktik hukuman penenggelaman ini bahkan dilakukan juga untuk banyak kasus, tidak terbatas hanya pada kasus perzinaan. Bahkan, kasus-kasus yang tampak ringan seperti kasus tuduhan tanpa

\footnotetext{
${ }^{29}$ Seperti yang dikatakan Ashley, "Thus the ordeal was related to divination as a method for discovering the divine will for a course of action" (Ashley, The Book of Numbers, 123).
}

alasan atau tanpa bukti bisa dihukum dengan cara demikian (Hukum Hammurabi §1-2).

If a man bring an accusation against a man, and charge him with a (capital) crime, but cannot prove it, he, the accuser, shall be put to death.

If a man charge a man with sorcery, and cannot prove it, he who is charged with sorcery shall go to the river, into the river shall throw himself and if the river overcome him, his accuser shall take to himself his house (estate). If the river show that man to be innocent and be come forth unharmed, he who charged him with sorcery shall be put to death. He who threw himself into the river shall take to himself the house of his accuser.

Jika dibandingkan dengan hukum yang tertulis di atas, tampak kontras dengan Taurat yang hanya memberlakukan ritual Sotah pada kasus kecurigaan terhadap wanita yang dianggap berzina. ${ }^{31}$ Jadi, Taurat membatasi praktik hukum pengujian seperti ini dan tidak diterapkan secara semena-mena pada kasus apa saja, selain kasus Bilangan 5:11-31. Dengan kata lain, ritual Sotah hanya diberikan secara unik untuk kasus kecurigaan yang spesifik ditujukan kepada wanita yang tertuduh tanpa adanya suatu bukti. Cara pembuktian ini meniadakan kemungkinan cara pembuktian liar lainnya yang berisiko membahayakan si tertuduh.

Kalaupun ritual Sotah itu tidak terhindarkan, dalam praktik ritual itu sendiri, risiko yang dihadapi seorang wanita tertuduh itu minim. Nissim Amzallag dan Shamir Yona berargumen bahwa larutan yang digunakan dalam ritual Sotah adalah larutan yang berisiko rendah untuk diminum. Kesimpulan ini diambil

\footnotetext{
${ }^{30}$ Seperti dikutip dalam Stol, Women in the Ancient Near East, 247.

${ }^{31}$ Herbert Chanan Brichto, "Case of the Sota and a Reconsideration of Biblical 'Law'," Hebrew Union College Annual 46 (1975): 55.
} 
dengan mempertimbangkan kata צִ ( ' $\bar{a} \cdot \bar{p} \bar{a} r)$ dalam Bilangan 5:17 sebagai komponen dari larutan yang digunakan dalam ritual tersebut. Akar kata עפר ini memang biasa dimengerti sebagai soil, earth of the grave, mortar, debris, ashes, atau dirt. ${ }^{32}$ Namun, Amzallag dan Yona menolak pendapat bahwa larutan yang digunakan dalam ritual Sotah itu berisi campuran tertentu, seperti kotoran atau darah yang tertinggal di sekitar kemah suci, yang mengakibatkan efek racun terhadap pelaku. ${ }^{33}$ Mereka juga menolak Sotah sebagai praktik sihir atau yang melibatkan kondisi psikosomatik. ${ }^{34} \mathrm{Se}$ baliknya, berdasarkan Ayub 28:2 dan juga konteks penambangan di pasal ini maka עפר dapat dipandang sebagai bijih (ore), yaitu bebatuan yang mengandung mineral logam. ${ }^{35}$ Kesimpulan ini dikonfirmasi di ayat 6 yang menyatakan bahwa batu lazurit (atau safir) mengandung

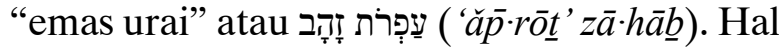
ini mengindikasikan bahwa עפר adalah sejenis mineral yang dipakai sebagai bahan pembentuk logam.

Dengan hanya meminum larutan mineral, kontras dengan debu, kotoran atau sihir yang bersifat racun dan mematikan, maka dapat dimengerti bahwa ritual Sotah dalam Alkitab berisiko rendah bagi wanita tertuduh. Amzallag dan Yona menyimpulkan, jika עפר dalam Bilangan 5:17 adalah unsur mineral logam, maka kemungkinannya hanya akan terjadi efek aborsi pada wanita yang sedang mengandung. Hanya dalam konsentrasi yang tinggi saja maka batu logam tersebut bisa menyebabkan efek racun. Jika mineral ini digunakan dalam ritual Sotah dengan konsentrasi yang wajar sesuai yang diatur dalam Bilangan 5:11-31, maka tidak akan membahayakan wanita yang sedang hamil muda, apalagi yang ternyata tidak hamil. ${ }^{36}$ Ditambah lagi, tidak

\footnotetext{
${ }^{32} \mathrm{BDB}, 779$.

${ }^{33}$ Nissim Amzallag dan Shamir Yona, "The Kenite Origin of the Sotah Prescription (Number 5.11-31)," Journal for the Study of the Old Testament 41 No. 4 (2017): 384-386, https://doi.org/10.1177/0309089216661176.

${ }^{34}$ Amzallag dan Yona, "The Kenite Origin,“ 386-388.
}

ada pernyataan yang jelas dalam pasal tersebut mengenai berapa lama larutan itu akan bekerja untuk membuktikan suatu kasus zina. ${ }^{37}$

Mengingat bahwa tersangka ada di bawah tuduhan kasus zina yang dalam tradisi Taurat harus dibebankan hukuman mati (Im. 20:10; Ul. 22:22), maka keunikan ritual Sotah dalam menanggulangi kasus zina ini menunjukkan anugerah ilahi yang besar atas pribadi yang tertuduh. Sebab, dalam kasus zina lainnya di Alkitab, seorang wanita tertuduh seharusnya langsung dijatuhi hukuman mati. Contoh kasus itu bisa dilihat dalam kisah Tamar yang dianggap berzina. Dari narasi itu dapat dimengerti bahwa hukuman bagi seorang wanita pezina atau pelacur adalah kematian, sekalipun ia sedang mengandung (lihat Kej. 38:24). Dari kisah ini juga bisa ditarik kesimpulan bahwa Yehuda tidak dibebankan hukuman sama sekali sekalipun ia yang menjadi inisiator perbuatan zina tersebut (Kej. 38:15-16). Kontras dengan itu, ritual Sotah berfungsi sebagai pencegah dan juga berfungsi untuk memperlambat proses menuju hukuman mati, terutama bagi bagi wanita tertuduh yang tidak bersalah, yang tidak seharusnya ditimpakan hukuman seberat itu. Karena itu, ritual Sotah ini bukannya merendahkan wanita, tetapi justru melindungi mereka dari hukuman yang mungkin tidak seharusnya diterima.

Tidak hanya itu, bahasa yang digunakan dalam Bilangan 5:11-31 tidak secara eksplisit menuduh si wanita sebagai yang sudah berdosa zina. Itulah sebabnya juga, konsep zina נאף tidak pernah disebutkan secara eksplisit dalam teks Bilangan 5:11-31, melainkan kata eufemistis (sth) yang lebih netral. Kata itu lebih berarti seorang perempuan yang berbuat serong atau tidak setia, dan bukan serta-

\footnotetext{
${ }^{35}$ Makna kata עפ sebagai bijih logam dalam Ayub 28:2 juga diakui oleh BDB, 779 dan $D C H$ 5:515.

${ }^{36}$ Amzallag dan Yona, "The Kenite Origin," 396.

${ }^{37}$ Frymer-Kensky, "The Strange Case of the Suspected Sotah," 24
} 
merta dikenakan label pezina. Konsekuensinya, ritual Sotah ini justru melihat tersangka tertuduh sebagai orang yang punya kemungkinan tidak bersalah. Kalaupun bersalah, ritual ini "reflects a surprisingly high level of tolerance in relation to adultery." 38

Ditambah lagi, penekanan kondisi cemburu yang membuat ritual Sotah ini tak terhindarkan justru memperjelas posisi legal dari kasus ini yang bisa dianggap tidak seberat kasus zina per se. ${ }^{39}$ Itulah sebabnya juga dalam tradisi Mishnah, para rabi Yahudi menyebut dan menamai kasus ini dalam satu kategori traktat Sotah. Maka, apa yang menjadi fokus dari kasus ini adalah wanita dan kemungkinan dari dosanya. Dengan kata lain, prosedur meminum larutan pahit itu merupakan suatu cara untuk menentukan apakah benar bahwa sang tertuduh itu adalah sotah. ${ }^{40}$ Ini memang ditekankan dalam Bilangan 5:29 yang menyim-

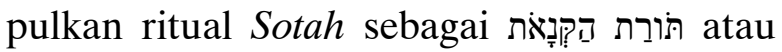
hukum tentang perkara cemburuan. Kata kunci yang sama juga diulang dalam teks di

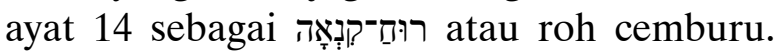
Briggs menyimpulkan dengan baik bahwa

It is the spirit of jealousy which work in this scenario, and the text offers a device for dealing with it. Thus what we have here is a procedure for dealing with the man's problem, and since his problem is caused by his wife, she is dragged into it. ${ }^{41}$

Ketiga, praktik ritual Sotah ini justru diberlakukan dengan maksud untuk menyelamatkan pihak tersangka dari hal yang lebih buruk. Jacob Milgrom misalnya, percaya bahwa hukum ini mengadopsi institusi hukum Timur Dekat Kuno, seperti hukum Hammurabi $\$ 132$ di atas, tetapi dengan maksud utama untuk menyelamatkan wanita dari aksi "main hakim

\footnotetext{
${ }^{38}$ Amzallag dan Yona, "The Kenite Origin," 404.

${ }^{39}$ Richard S. Briggs, "Reading the Sotah Text (Numbers 5:11-31): Holiness and a Hermeneutic Fit for Suspicion," Biblical Interpretation 17, no. 3 (2009): 288-319, https://doi.org/10.1163/156851508X329665.
}

sendiri” dari masyarakat setempat, yang hampir pasti akan diderita oleh seorang wanita yang menyandang reputasi sebagai seorang pezina. Kesimpulan Milgrom dapat dibenarkan oleh fakta hukum yang mengadili tindakan perzinaan yang berlaku di Timur Dekat Kuno. Dalam hukum Ur-Nammu (ca. 2112$2095 \mathrm{SM}$ ) pada baris 222-239 tertulis bahwa apabila istri dari seorang laki-laki, dengan pesonanya, mengikuti laki-laki lain dan tidur dengannya, para pemegang otoritas harus membunuh wanita itu, tetapi laki-laki yang berzina dengannya itu dibebaskan. ${ }^{42}$

Dalam kasus cemburuan lain, pria yang melihat istrinya sendiri berbuat zina berakhir dengan pembalasan dendam. Misalnya, Amsal 6:34-35, menjelaskan bagaimana seorang pria yang terbakar api cemburu akan menjadi dipenuhi amarah, tidak kenal belas kasihan dan akan melakukan pembalasan dendam. Ia tidak mau menerima tebusan apa pun, sekalipun pelakunya memaksa, bahkan dengan banyaknya pemberian. Dengan pria sebagai subjek pembicaraan (ay. 29) yang digambarkan menghampiri istri sesamanya, maka amarah cemburu ini akan ditimpakan kepada pelaku pria tersebut. Sang istri tidak menjadi sorotan penting di sini. Dengan demikian, dibakar oleh api cemburu, seorang pria akan menghukum mati orang yang berzina dengan istrinya itu.

Berbeda dengan kasus ini, pelaku yang berzina dengan istri dari korban dalam Bilangan 5:11-31 tidak diketahui identitasnya sebab tidak ada saksi. Sehingga, besar risiko dari sang istri untuk menerima api cemburuan suaminya itu yang bisa berakhir pada kematian. Cemburu yang dibakar oleh rasa curiga yang belum terbukti kebenarannya bisa berakhir dengan risiko yang mematikan. Karena itu,

${ }^{40}$ Ibid., 294.

${ }^{41}$ Ibid.

${ }^{42}$ James B. Pritchard ed., Ancient Near Eastern Texts Relating to the Old Testament, ed. ke-3 (Princeton: Princeton University Press, 1969), 524. 
ritual Sotah mengharuskan sang suami yang dengan cemburu mencurigai istrinya itu untuk membawa tersangka tertuduh ke hadapan imam (Bil. 5:15). Besar kemungkinan bahwa sebelum melakukan ritual ini, sang imam perlu memastikan bahwa apa yang dituduhkan kepada wanita itu telah terlebih dahulu memenuhi persyaratan dari klausa-klausa di ayat 11-14. Ini jelas adalah bentuk perlindungan bagi sang tertuduh.

Selain itu, keempat, jika dibandingkan dengan praktik Timur Dekat Kuno, hukum Taurat telah memberikan suatu keadilan yang cukup bagi sang wanita. Pritchard menunjukkan hukum dari kota Mesopotamia, Eshnunna (ca $1885 \mathrm{SM}$ ), bahwa pernikahan dipandang sebagai suatu kontrak antara suami dengan orang tua mempelainya. Karena itu, apabila istrinya itu kedapatan bersama dengan lakilaki lain, maka berlaku hukum, "Ia akan mati, ia tidak akan pergi dengan selamat." ${ }^{43}$ Dengan kata lain, seorang perempuan yang melanggar kontrak pernikahannya itu sudah sepantasnya menerima hukuman mati. Hukum Hammurabi (ca. 1792-1750 SM) menyatakan, "Jika seorang istri kedapatan berzina dengan laki-laki lain, maka ia akan diikat dan dilempar ke dalam air." ${ }^{44}$ Di catatan lain dalam hukum yang sama dikatakan, "apabila seorang suami mencurigai istrinya tetapi tidak memiliki bukti bahwa istrinya itu melakukan perzinaan, maka istrinya itu harus menjalani ritual penyiksaan dengan air, istrinya itu harus menceburkan diri ke dalam sungai." ${ }^{45} \mathrm{Ri}$ tual ini dilakukan karena sungai dianggap sebagai dewa. Karena itu, tenggelamnya wanita tersebut merupakan tanda salah yang disahkan oleh dewa tersebut. ${ }^{46}$ Hukum Asyur (ca. $1075 \mathrm{SM}$ ) memperbolehkan suami untuk

\footnotetext{
${ }^{43}$ James B. Pritchard, ed., The Ancient Near East: An Anthology of Texts and Pictures (Princeton: Princeton University Press, 1958), 135.

${ }^{44}$ Ibid., 152.

${ }^{45}$ James B. Pritchard, ed., The Ancient Near East, 152.

${ }^{46}$ Stol, Women in the Ancient Near East, 248.
}

memotong hidung istrinya yang dicurigai melakukan perzinaan. ${ }^{47}$ Kontras dengan praktik Timur Dekat Kuno yang mengharuskan seorang wanita tertuduh untuk selamat dari ritual yang membahayakan dan mematikan untuk membuktikan bahwa dirinya tidak bersalah, ritual Sotah tidak mengharuskan syarat ini dan membiarkan kasus itu tetap terbuka; mungkin si wanita itu bersalah atau mungkin saja tidak. ${ }^{48}$ Bahkan, mengomentari keunikan ritual Sotah dalam Alkitab tersebut, Rachel Biale benar dengan berkata,

How bad can it be to drink some water mixed with dust and ink? If survival here equals innocence, the likeliest outcome in Sotah is the proven innocence of the woman. ${ }^{49}$

\section{KESIMPULAN}

Secara sekilas, teks hukum Taurat Bilangan 5:11-31 bisa menimbulkan pertanyaan sosiologis mengenai posisi seorang wanita yang dipermalukan dalam ritual Sotah tentang kasus kecemburuan seorang suami. Sekalipun teks dalam Mishnah cenderung memberikan suatu penekanan penghinaan yang merendahkan kaum wanita, teks Taurat memberikan penekanan perlindungan terhadap kaum wanita di tengah budaya patriarki. Bahkan, di tengah hukum Timur Dekat Kuno yang tidak menguntungkan bagi posisi kaum wanita, Taurat memberikan keadilan yang cukup bagi mereka.

Dengan demikian, istri dalam kasus ini, tidak dirugikan. Malahan, Taurat memberikan perlindungan bagi istri sebagai kaum yang dianggap lemah dari sudut pandang budaya Timur Dekat Kuno. Apalagi, sistem budaya di sana

\footnotetext{
${ }^{47}$ Law I.15, "The Code of the Assura," Ancient History Sourcebook, Fordham University, https://sourcebooks. fordham.edu/ancient/1075assyriancode.asp.

${ }^{48}$ Ashley, The Book of Numbers, 123.

${ }^{49}$ Rachel Biale, Women and Jewish Law: An Exploration of Women's Issues in Halakhic Sources (New York: Schocken, 1984).
} 
memandang wanita secara inferior. Dari konteks posisi wanita pada budaya saat itu dan bagaimana Bilangan 5:11-31 ini berbeda secara unik dibandingkan ritual-ritual sejenis dan setempat, maka artikel ini menyimpulkan bahwa ritual Sotah dalam Alkitab justru diberikan sebagai sebuah terobosan budaya di tengah budaya di mana wanita dianggap inferior. Untuk itu, Taurat dalam Bilangan 5:1131 ini berfungsi sebagai penyeimbang dari budaya yang tidak menguntungkan kaum wanita. Taurat ini membela hak istri.

\section{REFERENSI}

Alpert, Rebecca T. "The Sotah Revisited." The Reconstructionist 53 (1988): 32-33.

Amzallag, Nissim dan Yona, Shamir. "The Kenite Origin of the Sotah Prescription (Numbers 5.11-31)." Journal for the Study of the Old Testament 41 no 4 (2017): 383412.

Ashley, Timothy R. The Book of Numbers. NICOT. Grand Rapids: Eerdmans, 1993.

Biale, Rachel. Women and Jewish Law: An Exploration of Women's Issues in Halakhic Sources. New York: Schocken, 1984.

Brichto, Herbert Chanan. "Case of the Sota and a Reconsideration of Biblical 'Law'." Hebrew Union College Annual 46 (1975): 55-70.

Briggs, Richard S. "Reading the Sotah Text (Numbers 5:11-31): Holiness and a Hermeneutic Fit for Suspicion," Biblical Interpretation 17, no. 3 (2009): 288-319. https://doi.org/10.1163/156851508X3296 65.

Brown, Francis, S.R. Driver dan Charles A. Briggs. The Brown-Driver-Briggs Hebrew and English Lexicon. Peabody: Hendrickson, 1994.

Clines, David J.A. Dictionary of Classical Hebrew. 9 Vol. Edisi revisi. Sheffield Academic Press, 2016.

Fishbane, Michael. "Accusations of Adultery: A Study of Law and Scribal Practice in
Numbers 5:11-31." Hebrew Union College Annual 45 (1974): 25-45.

Gruschcow, Lisa. Writing the Wayward Wife: Rabbinic Interpretations of Sotah, Ancient Judaism and Early Christianity 62. Leiden: Brill, 2006. https://doi.org/10. 1163/9789047417811.

Hauptman, Judith. Rereading the Rabbis: $A$ Woman's Voice. New York: Routledge, 2018.

Pritchard, James B., ed. Ancient Near Eastern Texts Relating to the Old Testament. Princeton: Princeton University Press, 1969.

- The Ancient Near East: An Anthology of Texts and Pictures. Princeton: Princeton University Press, 1958.

Budd, Philip J. Numbers. Vol. 5. WBC. Waco: Word, 1984.

Danby, H., ed. The Mishnah. London: Oxford University Press, 1933.

Driver, G.R. "Two Problems in the Old Testament Examined in the Light of Archaeology" T. 33 Fasc. 1/2. Syria (1956): 73-77.

Frymer-Kensky, Tikva. "The Strange Case of the Suspected Sotah" 34 no. 1. Vetus Testamentum (1984): 11-26. https://doi. org/10.1163/156853384X00025.

Harper, Robert Francis. The Code of Hammurabi: King of Babylon about 2250 B.C. Chicago: University of Chicago Press, 1904.

Levine, Baruch. Numbers 1-20: A New Translation with Introduction and Commentary. Anchor Bible Commentary. New York: Yale University Press, 1993.

MacDonald, Elizabeth Mary. The Position of Women as Reflected in Semitic Codes of Law. Toronto: University of Toronto Press, 1931.

Marsman, Hennie J. Women in Ugarit and Israel: Their Social and Religious Position in the Context of the Ancient Near East. Leiden: Brill, 2003.

McKane, William. "Poison, Trial by Ordeal and the Cup of Wrath" 30 no. 4. Vetus 
Testamentum (1980): 474-492. https://doi. org/10.1163/156853380X00434

Rosen-Zvi, Ishay. The Mishnaic Sotah Ritual:

Temple, Gender and Midrash. Supplements to the Journal for the Study of Judaism. Leiden: Brill, 2012. 